\title{
COMPARISON OF PV MODULE PERFORMANCE BEFORE AND AFTER 11-YEARS OF FIELD EXPOSURE
}

\author{
A.M. Reis, N.T. Coleman, M.W. Marshall, P.A. Lehman, and C.E. Chamberlin \\ Schatz Energy Research Center, Humboldt State University, Arcata, CA 95521
}

\begin{abstract}
In 1990 the Schatz Energy Research Center (SERC) installed a PV array comprised of 192 ARCO M-75 modules. Prior to installation, Zoellick [1] carefully measured module performance and reported average peak power at normal operating cell temperature (NOCT) to be $39.88 \mathrm{~W}$, which was $14.1 \%$ lower than the $46.4 \mathrm{~W}$ nameplate rating. For the past 11 years the array has been exposed to and employed in a cool, marine environment. Of the original 192 modules, 191 were recently tested in order to re-evaluate their performance.

This paper describes the equipment, conditions, and procedure used in retesting the modules, and reports module performance results. Notable results are that average module short circuit current and maximum power production at NOCT have decreased by $6.38 \%$ and $4.39 \%$, respectively.
\end{abstract}

\section{INTRODUCTION}

\section{Background}

In 1990 the Schatz Energy Research Center (SERC) installed a nominal $9.2 \mathrm{kWp}$ photovoltaic (PV) array (Figure 1) at Humboldt State University's (HSU) Telonicher Marine Laboratory in Trinidad, CA. The array is situated approximately 150 meters from the ocean in a cool, coastal environment. The PV system is an integral part of an ongoing solar hydrogen demonstration project. The primary function of the SERC array is to power an air compressor for HSU's marine laboratory. Excess power produced by the array is shunted to a Teledyne Energy ALTUS ${ }^{\mathrm{TM}} 20$ electrolyzer in order to produce hydrogen fuel for a proton exchange membrane (PEM) fuel cell. Together, the PV array and the PEM fuel cell power the air compressor 24 hours a day using renewable solar energy.

Prior to initial installation in 1990, the performance of each of the $192 \mathrm{PV}$ modules was measured [1]. From these tests, current versus voltage (I-V) curves and performance parameters were determined for each of the modules. In the current research, each of the modules was retested in order to generate updated I-V curves and performance parameters. These new data were compared to the original 1990 data to determine the extent to which each module's power production had degraded over time.

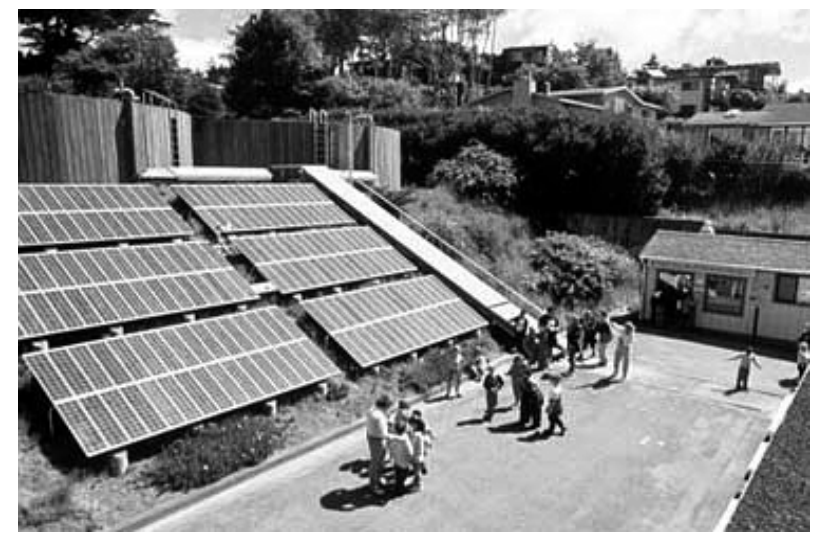

Figure 1. The SERC solar hydrogen project and the 192module PV array.

\section{Description of PV array and modules}

The SERC PV array consists of 192 photovoltaic modules configured into 12 independent subarrays tilted at $30^{\circ}$ from the horizontal. Each subarray consists of 16 modules wired in 8 series pairs for 24 VDC operation. All modules were originally $\mathrm{ARCO} \mathrm{M}-75$; one was replaced in 1996 by a Siemens model SM50-H module due to a shattered glass cover. The ARCO M-75 modules utilize single crystal silicon cells, which are laminated to tempered glass with ethylene vinyl acetate (EVA). Each module contains 33 solar cells and two bypass diodes. At standard test conditions (STC) $\left(1000 \mathrm{~W} / \mathrm{m}^{2}\right.$ and $\left.25^{\circ} \mathrm{C}\right)$ the modules have a $48 \mathrm{~W}$ maximum power $\left(P_{\max , S T C}\right)$ nameplate rating and at normal operating cell temperature (NOCT) $\left(1000 \mathrm{~W} / \mathrm{m}^{2}\right.$ and $\left.47^{\circ} \mathrm{C}\right)$ the modules have a 46.4 $\mathrm{W}$ maximum power $\left(P_{\max , N O C T}\right)$ nameplate rating. The nameplate rating for the short circuit current at NOCT $\left(I_{s c, N O C T}\right)$ is $3.72 \mathrm{~A}$.

\section{Previous findings}

In 1990 Zoellick determined that the modules' actual field performance was lower than their nameplate rating. Individually testing the 192 modules, Zoellick determined mean values and standard deviations for $P_{\max , \text { STC }}$ to be $43.71 \pm 0.871 \mathrm{~W}, P_{\max , N O C T}$ to be $39.88 \pm 0.849 \mathrm{~W}$ and $I_{s c, N O C T}$ to be $3.29 \pm 0.044 \mathrm{~A}[1]$. These values are $8.9 \%$, $14.1 \%$, and $11.6 \%$ below their respective nameplate ratings. 


\section{Current research}

The remaining 191 ARCO M-75 modules were retested in order to evaluate module performance. The performance parameters investigated in this study are the open circuit voltage $\left(V_{o c}\right)$, short circuit current $\left(I_{s c}\right)$, series resistance $\left(R_{s}\right)$, parallel resistance $\left(R_{p}\right)$, a lumped parameter describing the degree of knee curvature $(e k t)$, maximum power point $\left(P_{\max }\right)$, maximum power point voltage $\left(V_{m p}\right)$, and maximum power point current $\left(I_{m p}\right)$. Figure 2 shows what each of these parameters represents on an I-V curve.

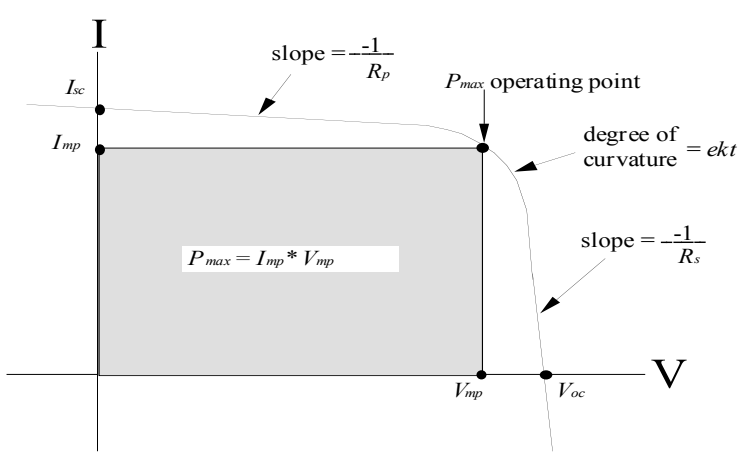

Figure 2. A typical I-V curve demonstrating the function of the performance parameters.

\section{PROCEDURE}

\section{Testing conditions}

The modules in the SERC solar hydrogen PV array were tested in the field at the angle of the array. Testing of the modules began September 18, 2000 and concluded June 15, 2001. No testing was done between October 28, 2000 and March 2, 2001. All modules were tested within two hours of solar noon with module temperatures ranging from $26.5^{\circ} \mathrm{C}$ to $62.5^{\circ} \mathrm{C}$. The measurements were conducted under clear sky conditions with irradiance values greater than $800 \mathrm{~W} / \mathrm{m}^{2}$. A typical I-V curve required about 1.5 seconds to generate. The short duration of the I$\mathrm{V}$ curve traces allowed values for solar irradiance and module temperature to remain stable during the test.

It was our intent to match the testing procedures applied by Zoellick [1]. Two aspects of the testing procedures differed: 1) Modules were retested in the array frame whereas Zoellick used a portable testing frame on which the pyranometer was also mounted. 2) The current research utilized a newer data acquisition system.

\section{Data collection apparatus}

The module I-V curve data were collected using a LabVIEW $^{\mathrm{TM}}$ 5.0-based program on a PowerComputing PowerCenter 150 computer with a National Instruments PCI-MIO-16XE-50 data acquisition board installed. The board was connected to an Analog Devices 5B01 16channel backplane. The backplane was fitted with four $5 \mathrm{~B}$ series signal conditioning modules. Data acquisition was set at $100 \mathrm{~Hz}$.
Voltage and current signals from the PV modules were conditioned using Analog Devices 5B40-02 isolated wideband millivolt input modules. Irradiance was measured using an Eppley PSP pyranometer at the same $30^{\circ}$ tilt angle as the PV array. The pyranometer signal was conditioned using Analog Devices 5B30-01 isolated millivolt input modules. Module temperature was measured using an Omega CO1-T fast response type-T thermocouple. The temperature signal was conditioned using an Analog Devices 5B47-T-07 isolated linearized type-T thermocouple input module.

\section{Module preparation}

Before testing a subsection of the array, the cover glass of each of the modules in that subsection was cleaned in order to remove any residue that had accumulated. Individual modules were unbolted, and removed from the frame prior to testing. The module was then electrically disconnected from the remainder of the PV array and connected across the capacitive load test circuit in order to generate the I-V curve. To determine the module operating temperature, the thermocouple was attached to the back of the module near the center. The module was then replaced into the array frame and allowed to return to a steady-state temperature before the I-V curve was measured.

\section{Collection and standardization of I-V curve data}

Four parameters were measured and recorded during the I-V curve trace for each module: 1) module voltage, 2) module current, 3) module temperature, and 4) solar irradiance in the plane of the module. Two I-V curves were measured for each module. The individual current/voltage pairs of the I-V curve were then corrected to STC and NOCT using the same correction factors (Table 1) as those used by Zoellick [1]. The $V_{o c}$ correction factors were used to correct the observed module $V_{O C}$ to STC and NOCT. A ratio of $V_{o c}$ (corrected) divided by $V_{o c}$ (observed) was determined and this ratio was then used to correct the voltage in each current/voltage pair. The current in each current/voltage pair was adjusted by multiplying the observed current by $1000 \mathrm{~W} / \mathrm{m}^{2}$ and then dividing by the observed solar irradiance. Correcting current for module temperature was deemed unnecessary. In order to validate the correction factors, $30 \mathrm{I}-\mathrm{V}$ curves were generated for one panel under varying temperature and irradiance conditions. Statistical analysis of these data indicated that the original correction factors were still valid.

Table 1. Correction factors used to correct actual data to STC and NOCT.

\begin{tabular}{|c|l|l|}
\hline Parameter & \multicolumn{1}{|c|}{ Correction for: } & \multicolumn{1}{c|}{ Correction Factor } \\
\hline \hline$V_{o c}$ & Module Temperature & $-0.0603 \mathrm{~V} /{ }^{\circ} \mathrm{C}$ \\
\hline$V_{o c}$ & Solar Irradiance & $0.0009296 \mathrm{~V}^{*} \mathrm{~m}^{2} / \mathrm{W}$ \\
\hline$I$ & Solar Irradiance & $\begin{array}{l}\left(1000 \mathrm{~W} / \mathrm{m}^{2}\right) /(\text { Actual } \\
\text { Irradiance })\end{array}$ \\
\hline
\end{tabular}

The I-V curve of a module can be described using a five-parameter model developed by Lehman and Chamberlin [2]. This model mathematically represents the 
I-V curve data of a module using the following five parameters: $V_{o c}, I_{s c}, R_{s}, R_{p}$, and ekt. The five-parameter model (Equation 1) is shown below:

$$
I=I_{s c}-\left[\frac{I_{s c}-\frac{V_{o c}}{R_{P}}}{\exp \left(e k t \cdot V_{o c}\right)-1}\right]\left\{\exp \left[\operatorname{ekt}\left(V+R_{s} I\right)\right]-1\right\}-\frac{\left(V+R_{s} I\right)}{R_{p}}
$$

where:

$$
\begin{array}{ll}
I & =\text { Module output current }(\mathrm{A}) \\
V & =\text { Module voltage }(\mathrm{V}) \\
I_{s c} & =\text { Short circuit module current }(\mathrm{A}) \\
V_{o c} & =\text { Open circuit module voltage }(\mathrm{V}) \\
R_{s} & =\text { Module series resistance (Ohms) } \\
R_{p} & =\text { Module parallel resistance (Ohms) } \\
e k t & =\frac{q}{n k T}\left(\mathrm{~V}^{-1}\right) \\
q & =\text { Electron charge (Coulomb) } \\
n & =\text { Ideality factor per cell (unitless) } \\
k & =\text { Boltzmann's constant (Joule/K) } \\
T & =\text { Temperature (K) }
\end{array}
$$

The five-parameter model was fitted to the corrected NOCT data obtained from each I-V curve run. Values for each of the five parameters in the model were calculated using a customized version of the LabView nonlinear Levenberg-Marquardt algorithm to determine the set of coefficients that best fits the data based on a least squares criterion. PV module degradation was assessed by comparing the newly generated I-V curves and performance parameters to those generated in 1990 when

\begin{tabular}{|c|c|c|c|c|c|}
\hline \multirow[b]{2}{*}{ Parameter } & \multicolumn{2}{|c|}{1990} & \multicolumn{2}{|c|}{2001} & \multirow[b]{2}{*}{$\%$ Change } \\
\hline & $\bar{x}$ & $S_{x}$ & $\bar{x}$ & $s_{x}$ & \\
\hline$P_{\max }(\mathrm{W})$ & 39.88 & 0.849 & 38.13 & 1.67 & -4.39 \\
\hline$V_{O C}(\mathrm{~V})$ & 18.19 & 0.131 & 18.15 & 0.108 & -0.22 \\
\hline$I_{s c}(\mathrm{~A})$ & 3.29 & 0.044 & 3.08 & 0.120 & -6.38 \\
\hline$R_{S}(\mathrm{Ohms})$ & 0.347 & 0.115 & 0.384 & 0.184 & 10.66 \\
\hline$R_{p}(\mathrm{Ohms})$ & 171 & 39.2 & 115 & 48.7 & -32.75 \\
\hline$e k t\left(\mathrm{~V}^{-1}\right)$ & 0.709 & 0.125 & 0.896 & 0.26 & 26.38 \\
\hline$V_{m p}(\mathrm{~V})$ & 13.9 & 0.20 & 14.2 & 0.33 & 2.16 \\
\hline$I_{m p}(\mathrm{~A})$ & 2.88 & 0.033 & 2.69 & 0.111 & -6.60 \\
\hline
\end{tabular}
the modules were initially installed.

\section{RESULTS}

A mean comparison of the 191 individual module parameter estimates at NOCT is given in Table 2. The most important result is the decrease in $P_{\max }$ from $39.88 \mathrm{~W}$ to $38.13 \mathrm{~W}$. This represents a $4.39 \%$ drop in the average maximum power produced by individual modules during the 11 years they have been in operation.

Table 2. Comparison of mean value $(\bar{x})$ and standard deviation $\left(s_{x}\right)$ of module parameters from 1990 and 2001 at NOCT.

There was very little change in $V_{o c}$, indicating that the majority of the power loss in the modules is due to decreased current producing capability as evidenced by the decrease in $I_{s c}$ and $I_{m p}$. By observing the values for $V_{m p}$ and $I_{m p}$, one notices that the maximum power point has shifted further down the knee of the I-V curve. Also worth noting are the increase in $R_{s}$ and the decrease in $R_{p}$, both of which decrease module performance.

The histogram in Figure 3, showing the distribution of $P_{\text {max }}$ at NOCT, indicates that the maximum power has decreased since 1990. The variability in maximum power within the modules has significantly increased as can be seen by the larger range of $P_{\max }$ values.

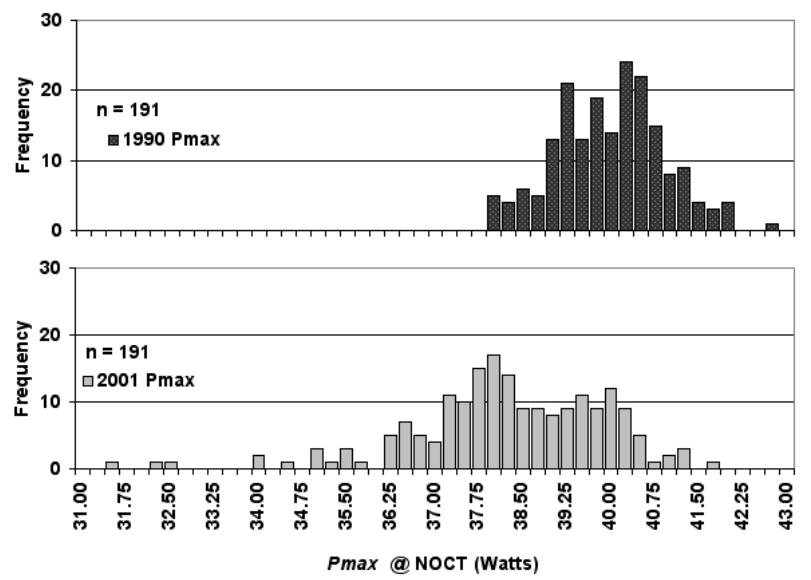

Figure 3. Comparison of $P_{\max }$ distribution between 1990 and 2001.

Figure 4 is a histogram of the $V_{o c}$ distribution at NOCT in 1990 and 2001. This histogram demonstrates that the distribution of $V_{o c}$ has not changed substantially over the 11 -year period the modules have been in operation.

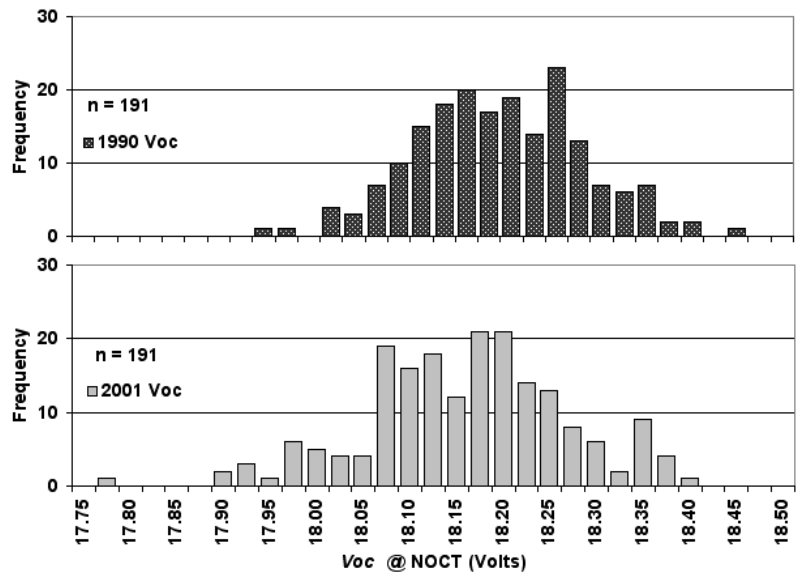

Figure 4. Comparison of $V_{o c}$ distribution between 1990 and 2001.

The short circuit current, $I_{s c}$, however, changed considerably between 1990 and 2001 as can be seen in Figure 5. Overall, most of the modules produce less current today than they did when they were new. A few of the modules actually exhibit a higher short circuit current. This increase in $I_{s c}$ will be explained in the following section. 


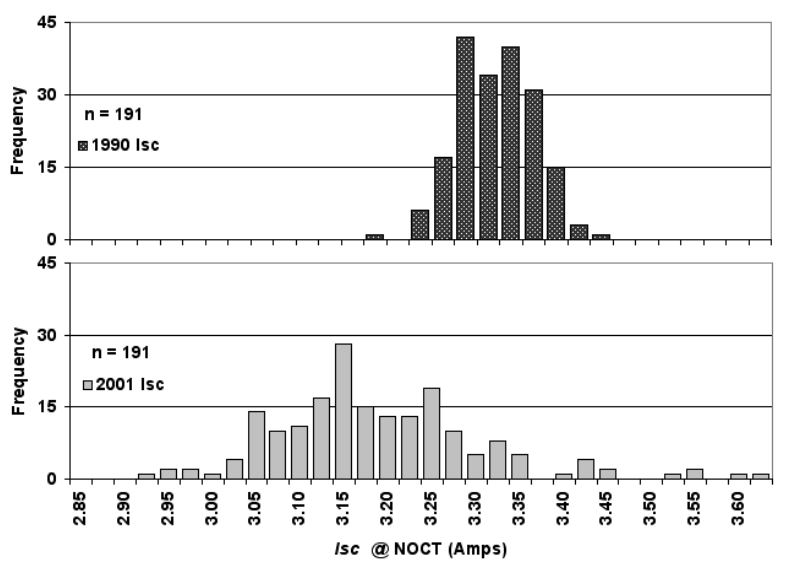

Figure 5. Comparison of $I_{s c}$ distribution between 1990 and 2001.

\section{DISCUSSION}

As Table 2 indicates, the average $P_{\max }$ for the remaining 191 ARCO M-75 panels has decreased by $4.39 \%$ after 11 years of use in the field. The reduction in $P_{\max }$ is primarily due to a decrease in current output as demonstrated by the lowered values of $I_{s c}$ and $I_{m p}$. This reduction in the amount of current generated is believed to be caused in part by the following visually observable physical defects:

1) Mild discoloration or browning of the EVA encapsulant over every cell in the module [4].

2) Delamination of the EVA encapsulant at the silicon cell-EVA interface [5].

3) Intense browning of the EVA above individual cells, presumably caused by localized hot spots [6].

The percent decreases observed in the performance parameters $P_{\max }, I_{s c}$ and $V_{o c}$ (Table 2 ) are below the range reported for $\mathrm{PV}$ modules that have been in the field for five or more years. Machida, Yamazaki, and Hirasawa [3] investigated the degradation of individual single crystalline PV modules and reported a percent decline in $P_{\max }$ of $4.8 \%$, in $I_{s c}$ of $5.3 \%$ and a minimal change in $V_{o c}$ after five years of field exposure. The SERC modules had similar levels of degradation after 11 years of field exposure. The lower annual degradation rate of the SERC modules might be attributed to the lower ambient temperatures they are exposed to throughout the year in their coastal environment. Modules have been reported to degrade faster when subjected to higher ambient and operating temperatures [4].

A few of the SERC modules actually exhibited a higher $I_{s c}$ compared to when they were initially installed (Figure $5)$. This was noticed in approximately one-third of the modules that had one of their bypass diodes activated during the I-V curve trace. When a bypass diode activates, two of the three 11-cell strings in the module are bypassed. If the cell that normally limits current production is in one of the two bypassed strings, a different cell will limit current in the remaining 11-cell string. Thus, short circuit current produced by the active string of cells must necessarily be higher than the original $I_{s c}$ if the string containing the cell that normally limited current is removed from the circuit.

Changes in module resistances (Table 2) have also caused a decrease in module performance. The increased series resistance $\left(R_{S}\right)$ causes a greater amount of the generated power to be lost as heat. A decrease in parallel resistance $\left(R_{p}\right)$ indicates an increase in current leakage around the cells. Both phenomena reduce the amount of current available for useful work.

\section{CONCLUSION}

Since initial installation in 1990, the average module in the SERC PV array has decreased in performance. Even though there was little change in the average value of $V_{o c}$, the short circuit current $\left(I_{s c}\right)$ has on average decreased $6.38 \%$ leading to an average $4.39 \%$ decrease in $P_{\text {max. }}$. The drop in current production by the modules can be attributed in part to the visually observable physical defects including EVA browning, delamination at the Sicell/EVA interface and the occurrence of localized hot spots. The observed percent decrease in performance is considered quite low compared to that of other field deployed modules. Considering the close proximity of SERC's array to the Pacific Ocean and the corrosive environment in which it exists, the modules are performing remarkably well.

\section{REFERENCES}

[1] J.I. Zoellick, "Testing and matching photovoltaic modules to maximize solar electric array performance", Senior project presented to the Department of Environmental Resources Engineering Humboldt State University (1990)

[2] P.A. Lehman and C.E. Chamberlin, "Field measurements of flat-plate module performance in Humboldt County, California", Nineteenth IEEE PVSC, New Orleans, LA (1987)

[3] K. Machida, T. Yamazaki, and T. Hirasawa, "Secular degradation of crystalline photovoltaic modules", Solar Energy Materials and Solar Cells, Volume 47 (1997) pages 149-153

[4] A.W. Czanderna and F.J. Pern, "Encapsulation of PV modules using ethelyne vinyl acetate copolymer as a pottant: A critical review", Solar Energy Materials and Solar Cells, Volume 43 (1996) pages 101-181

[5] N.G. Dhere, N.R Raravikar, "Adhesional shear strength and surface analysis of a PV module deployed in a harsh coastal climate", Solar Energy Materials and Solar Cells, Volume 67 (2001) pages 363-367

[6] D.L. King, J.A. Kratchovil, M.A. Quintana, and T.J. McMahon, "Applications for infrared imaging equipment in photovoltaic cell, module, and system testing", Twenty-eighth IEEE PVSC (2000) pages $1487-1490$ 